\title{
Elisabeth Bonnier Noel-Croulard
}

\section{Alina Wong}

\section{(2) OpenEdition Journals}

Edición electrónica

URL: http://journals.openedition.org/bifea/2925

DOI: $10.4000 /$ bifea.2925

ISSN: 2076-5827

\section{Editor}

Institut Français d'Études Andines

\section{Edición impresa}

Fecha de publicación: 1 abril 2009

Paginación: 163-169

ISSN: 0303-7495

\section{Referencia electrónica}

Alina Wong, «Elisabeth Bonnier Noel-Croulard », Bulletin de l'Institut français d'études andines [En línea], 38 (1) | 2009, Publicado el 01 octubre 2009, consultado el 19 noviembre 2020. URL : http:// journals.openedition.org/bifea/2925; DOI : https://doi.org/10.4000/bifea.2925

Les contenus du Bulletin de l'Institut français d'études andines sont mis à disposition selon les termes de la licence Creative Commons Attribution - Pas d'Utilisation Commerciale - Pas de Modification 4.0 International. 


\section{ELISABETH BONNIER NOEL-CROULARD}

1949-2009

Una gran pérdida para la arqueología peruana y sobre todo para el estudio de la arquitectura prehispánica es el deceso de la Dra. Elisabeth Bonnier, arqueóloga peruanista francesa, quien nos dejó el pasado 11 de enero de 2009 víctima de una penosa enfermedad en la ciudad de Providence (Rhode Island, USA).

Salida de las canteras de la Université de Paris X-Nanterre, miembro del Laboratorio de Prehistoria del Musée de l'Homme dirigido por H. de Lumley, con experiencia en el campo llevada a cabo en la excavación de una villa gallo romana y de un asentamiento magdaleniense en Pincevent (Francia), Elisabeth Bonnier llegó al Perú en 1974, año en el que obtuvo su Maîtrise en Histoire de l'Art et Archéologie, dirigida por el Dr. René Ginouvés y el Dr. Henri Reichlen. Su tesis de investigación se basó en el estudio morfológico de las vasijas enteras de la cultura Chancay ${ }^{1}$ que provenían de la costa norcentral del Perú (colección perteneciente al Musée de l'Homme de París). Fue un trabajo de orientación metodológica y fue presentado en coautoría con Catherine Rozenberg —ambas amigas entrañables, compañeras de estudio y colegas-. Este primer acercamiento marcaría sus futuras investigaciones.

Entre 1975 y 1982 ambas participan en la Misión Arqueológica Francesa de JunínPalcamayo del Centre National de la Recherche Scientifique (CNRS) y del Ministerio de Relaciones Exteriores (MAE) dirigida por la Dra. Danièle Lavallée (Lavallée et al., 1995: xviii)2. Dentro del marco de este proyecto, E. Bonnier y C. Rozenberg excavaron en el abrigo de Telarmachay (San Pedro de Cajas) y también trabajaron durante 3 temporadas (19761978) en la cuenca del Shaka (Palcamayo, Junín), donde realizaron sus investigaciones. Sustentaron sus resultados en 1982 con la tesis de Doctorado de 3ème Cycle titulada «L'Occupation humaine dans le bassin du Shaka-Palcamayo à I'Intermédaire Récent, Andes centrales du Pérou», bajo la dirección de Nathan Wachtel y presentada en la Université Paris X-École des Hautes Études en Sciences Sociales. Los puntos más importantes de aquella investigación son la secuencia cronológica, la excavación y el registro de sitios arqueológicos que constituyen un caso representativo de la arquitectura regional. E. Bonnier estudia el hábitat del Intermedio Tardío, incluyendo la organización y distribución del espacio aldeano agropastoril y doméstico, específicamente de dos ecosistemas: suni y puna. Según los datos recuperados entonces remarcamos los hallazgos de dos recursos muy importantes para la subsistencia prehispánica en la zona: la maca (Lepidum Meyenii)3 y la explotación de la sal (Bonnier \& Rozenberg, 1982: 21, 179. Ver tesis Vol. 1: Cachipuquio).

Poco antes del fallecimiento de Bertrand Flornoy, en abril de 1980 (Bonnier \& Rozenberg, 1987: 3-4), y gracias al impulso de este estudioso apasionado — miembro fundador de la Société des Explorateurs et des Voyageurs Français, quien había estudiado en los años 1950-1960 los sitios arqueológicos del valle de Tantamayo (Provincia de Huamalíes, dpto. de Huánuco) (Flornoy, 1957; Laclavère, 1981)—y a las excavaciones realizadas por Louis

1 Su Mémoire de Maîtrise fue titulada Analyse morphologique de la céramique Chancay. La síntesis de este trabajo fue presentado en Bonnier \& Rozenberg (1977).

2 E. Bonnier y C. Rozenberg fueron miembros del equipo de la Dra. Danièle Lavallée, URA n. ${ }^{\circ} 25$ «Prehistoria de las Regiones Andinas» (CNRS) (Rozenberg, C., 2009: comunicación personal).

3 Restos carbonizados de esta planta alimenticia y también usada como planta medicinal hasta nuestros días fue registrada en tres sitios arqueológicos de la cuenca (Bonnier, 1986: 101; Bonnier \& Rozenberg, 1982: 116, 145 150. Ver tesis Tomo 1). 
Girault en 1968 y 1970 en Piruru4, Elisabeth Bonnier y Catherine Rozenberg siguen el derrotero de sus antecesores y se encargan de la dirección del Proyecto Tantamayo Piruru con el objetivo de continuar con las investigaciones en la zona.

Este proyecto fue financiado por el Ministerio de Relaciones Exteriores de Francia (MAECommission Consultative des Recherches Archéologiques à l'Étranger) y formó parte de los programas de investigación del Instituto Francés de Estudios Andinos. Las dos fueron investigadoras del IFEA con el estatuto de «Pensionnaire» entre los años 1982 y 1986. E. Bonnier fue responsable de la conducción de las excavaciones, análisis estratigráfico y el estudio de la arquitectura en Piruru, mientras que C. Rozenberg se hizo cargo del estudio del material arqueológico, dando énfasis al surgimiento de las primeras cerámicas y su estudio comparativo con otras, más tempranas, de los Andes centrales (Bonnier \& Rozenberg, 1981: 19).

Se llevaron a cabo 7 temporadas de campo, las primeras 6 entre 1980 y 1985 . Situándonos en el contexto político del Perú de aquella época, hay que mencionar que Huánuco y en particular Tantamayo fueron tocados por la violencia terrorista duranta la década de 1980, específicamente en 1984 cuando todos los participantes del proyecto arqueológico fuimos testigos del abandono de las comisarías apostadas en la carretera Huánuco-Tantamayo por parte de las fuerzas policiales. Luego, en noviembre de ese mismo año, se produjo una incursión senderista en el pueblo de Tantamayo (Ocaña Lago, 2007), que bastó para ser declarada zona liberada y en estado de emergencia un tiempo después. A pesar de esa inestabilidad, en 1985 se siguió trabajando en Piruru, concretándose con mucho esfuerzo una última temporada de campo en 1988. Los estudios de laboratorio (entre 1989 y 1990) fueron financiados con sus propios recursos y con la ayuda de pequeñas becas ofrecidas por la ORSTOM, Ilamada actualmente IRD (Institut de la Recherche pour le Développement). Colaboraron activamente con este proyecto estudiantes de la Escuela de Arqueología de la Universidad Nacional Mayor de San Marcos5, así como pobladores de los pueblos de Coyllarbamba y Tantamayo.

El pequeño valle de Tantamayo, situado en la cordillera oriental de los Andes sobre la margen derecha del río Marañón, ofrece una gran concentración de sitios arqueológicos, la mayoría de ellos asentados entre los 3800 y de 4200 msnm. En 1980 E. Bonnier realizó una prospección en el valle (Bonnier, 1981: 1), registrando 81 sitios arqueológicos en un área de $65 \mathrm{~km}^{2}$, lo que confirma la tesis de Tantamayo como el centro de la mayoría de sitios (sitios de hábitat, sitios defensivos, terrazas, depósitos, corrales). El sitio de Piruru, ya excavado por L. Girault en 1968 y 1970, había dejado la pauta sobre su importancia arqueológica.

Las excavaciones en el sitio de Piruru muestran una larga secuencia de ocupación, que va desde el Precerámico tardío o Arcaico tardío (arquitectura ceremonial) y el Formativo (aldeas: construcciones domésticas), hasta el Intermedio Tardío (aldea fortificada) y la posterior ocupación Inca, con un hiatus entre el Intermedio temprano y el Horizonte Medio6.

4 Trabajo trunco debido a su muy temprano fallecimiento en 1975 en la ciudad de La Paz (Saignes, 1979; Girault, 1981. Fouilles sur le site de Piruru en 1968 et 1970, publicado por Bonnier \& Rozenberg, 1987: 4).

5 Para los estudiantes sanmarquinos que participaron en las excavaciones y en los trabajos de laboratorio, fue una escuela de campo. Aquí una relación de ellos: María Dianderas, Manuel Calderón, Muriel Pozzi-Escot, Andrés Mendiola, Elizabeth Isla, Carlos Farfán, Carmen Rosa Cardoza, Juan Carlos Tello, Julio Zegarra, Luis Lumbreras Flores, Marcela Ramírez, José Pablo Baraybar, Alina Wong, Elmer Atalaya, Johnny Isla, Mario Ruales, Liz Padilla Jorge Villavicencio, Aldo Bolaños, Carlos del Águila, Fernando Fujita, Juan Paredes, Víctor Manuel Ponte, Daniel Guerrerot, Abraham Zevallos, Diego Guevara.

6 No hay registros de material diagnóstico para estos períodos (Bonnier, 1983: 8-10; 1987: 6). 
Elisabeth Bonnier enfocó su investigación en la interpretación de la morfología arquitectónica en su contexto estratigráfico en respuesta a los rasgos presentes en la Plataforma P1 de Piruru y su análisis comparativo con otros sitios de la sierra con arquitectura precerámica (Ancash y Huánuco). La arquitectura ceremonial y monumental, estratigrafía y datación de los sitios de sierra como La Galgada, Huaricoto, Shillacoto (principalmente Kotosh), fueron reexaminados por ella y se pudo definir un estilo arquitectónico propio de la sierra que denominó: la Tradición Mito (Bonnier, 1987; 1988b; Bonnier \& Rozenberg,1988a: 989).

En 1987 se realizó el «ler Symposium Arquitectura y Arqueología. Pasado y futuro de la construcción en el Perú», Ilevado a cabo en Chiclayo (dpto. de Lambayeque), en el que E. Bonnier participó, dentro de la Primera Mesa Redonda: «Arquitectura y Urbanismo prehispánico» (al lado del arquitecto Carlos Williams), y presentó los datos sobre la arquitectura precerámica de Piruru, utilizando dos nuevos términos o neologismos para identificar las diferentes áreas dentro del templete: Epicausto (piso-altar) y Pericausto (banqueta) (Bonnier, 1988a: 347) —donde el fogón es el elemento central—. Otro elemento singular de esta tradición es el uso del sedimento rojo. La ubicación cronológica en base a los fechados 14C datan aproximadamente entre los 2500-2000 a.C. para esta arquitectura. Nuevas técnicas de construcción también fueron registradas: el uso de los sillares, la presencia (al parecer) de paredes de «quincha» para la Plataforma Mito y de la falsa bóveda en la estructura subterránea de la Unidad I/II (Bonnier et al., 1985: 95, estructura $\mathrm{H})$.

En artículos posteriores planteó nuevas formas arquitectónicas a partir de los vestigios descubiertos en las últimas temporadas de campo en Piruru. Nos referimos a los templetes Pre Mito (Bonnier, 1988b: 354), construcciones no tan elaboradas como el templete Mito, que no tienen el detalle de la banqueta ni el piso a doble nivel, pero sí presentan el fogón y el piso que cumplen la función principal del altar para los rituales, evidenciando una larga tradición litúrgica con cánones ya establecidos y por ende, una fuerte tradición cultural religiosa para el área del Alto Marañón y del Callejón de Huaylas.

E. Bonnier utilizó la arquitectura de Piruru como indicador del cambio de funcionalidad del sitio. Primero reconoció el carácter sagrado del sitio: un lugar destinado al culto que, sin duda, fue un santuario para el Arcaico Tardío - la característica de este tipo de arquitectura es la limpieza ritual a excepción de los restos de prácticas rituales (a manera de ritos de cremación) con algunos objetos votivos-. Después de que Piruru fuera utilizado como santuario, el sitio cambia radicalmente de uso pues se registra una arquitectura doméstica, base para el proceso de sedentarización, y se evidencia la introducción de las primeras cerámicas (Fase Piruru-Pirwa) (Bonnier \& Rosenberg, 1988a).

En 1988 organizó y presidió el symposium «Prehispanic architecture and civilization in the Andes» dentro del $46^{\circ}$ Congreso Internacional de Americanistas, realizado en Amsterdam (Holanda). Éste reunió a arqueólogos de dos escuelas — la americana y la europea-, cuyas diferencias, tanto en la práctica como en la interpretación arqueológica, enriquecieron el debate y se complementaron. No solo trataron el tema del estudio de la arquitectura en los Andes peruanos, sino también la evolución de las técnicas constructivas, el análisis de la forma y la funcionalidad de la construcción a través del tiempo y del espacio. Coincidieron en la necesidad de afinar cronologías para ubicar los monumentos y el arte monumental en su preciso tiempo y dar sustento a las sociedades que los crearon. También se renovó el interés en la arquitectura andina y en la necesidad de incrementar las investigaciones (Bonnier \& Bishof, 1997).

Las actas de este simposio fueron finalmente publicadas en 1997 con la ayuda del Dr. Henning Bischof y la Sociedad Arqueológica peruano-alemana del Reiss-Museum de Mannheim con el título Arquitectura y civilización en los Andes prehispánicos = Prehispanic 
architecture and civilization in the Andes (Elisabeth Bonnier \& Henning Bischof, eds.). Dos trabajos fueron presentados por E. Bonnier: el primero, basado en sus estudios del valle del Shaka-Palcamayo sobre la morfología de los asentamientos aldeanos de los grupos étnicos Chinchaycocha Tarama del Intermedio Tardío y su análisis comparativo con otros sitios de los Andes centrales; y el segundo, versó sobre la arquitectura precerámica (Tradición Mito) del sitio de Piruru y de la revisión a detalle de las evidencias publicadas en Andes 4: Excavations at Kotosh. Peru, 1963 and 1966 del montículo KT del período Kotosh Mito (Izumi \& Terada eds., 1972).

Dedicó un periodo a su vida a la docencia en la Pontificia Universidad Católica del Perú, dentro de la Maestría de la Escuela de Graduados del Departamento de Humanidades (Arqueología). Entre 1987 y 1988 dictó el curso «Temas de Arqueología: Arquitectura, estratigrafía y cronología». En 1989 participó en la propuesta del desarrollo museográfico del Nuevo Museo (actualmente Museo de la Nación) para el montaje de la sección del Precerámico final o Arcaico tardío. Integró el sitio de Piruru —específicamente la Plataforma P1 - como muestra de la arquitectura de la Tradición Arquitectónica Mito al panorama de la arquitectura ceremonial temprana, al lado de la reconstitución a escala del Templo de las Manos Cruzadas de Kotosh.

Dejó el Perú en 1990 para establecerse con su familia en Rhode Island (Providence, USA). También ejerció la docencia en Rhode Island School of Design, tuvo a su cargo distintos cursos como «Historia del Arte precolombino», «Visualizando la antigua Arquitectura», «Arquitectura precolombina», «Urbanismo y Arquitectura del pasado: un acercamiento digital interactivo», entre otros.

Fruto de su intensa relación con la arquitectura precolombina, la arqueología, la docencia en RISD y el avance de las nuevas técnicas digitales de presentación, podemos hoy observar Piruru Interactivo, un trabajo diseñado por su alumno Matt Sundstrom, durante el curso llamado «Urbanism and Architecture of the Past: A Digital Interactive Approach», que dictó en el año 20077. Matt se basó en los datos de la Unidad V de Piruru y presenta de forma más visual e interactiva un ensayo de la reconstitución de las diferentes fases del proceso constructivo realizado en ese sector del sitio arqueológico.

Más adelante, E. Bonnier se integró al medio académico norteamericano de andinistas, participando en los Annual Northeast Conference on Andean Archaeology and Ethnohistory como expositora en varias oportunidades y en 1995, al lado de Edward Dwyer, como organizadora de la $14^{\circ}$ Conferencia que se llevó a cabo en Providence, su lugar de residencia. También participó en varios Annual Meeting of Institute of Andean Studies en Berkeley, incluyendo el último realizado en 2008 con el artículo «A Picture or a Thousands words? Early andean architecture in 3D».

En el año 2003 regresó al Perú, después de asistir al «51 ${ }^{\circ}$ Congreso Internacional de Americanistas» realizado en Santiago de Chile, y fue una manera de volver a los orígenes y a los Andes. A partir de esa fecha y en todos sus viajes posteriores, tuve oportunidad de acompañarla. En 2003 viajamos al departamento de Junín y visitamos San Pedro de Cajas, el lago Chinchaycocha, Óndores y Pachamachay; luego enrumbamos a Húanuco, pasando por Singa — un nuevo destino- y Tantamayo. Retornando a Lima visitamos el valle de Casma, aunque siempre con el objetivo de recabar información sobre los sitios del Intermedio Tardío y de arquitectura monumental temprana, sus principales temas de investigación.

7 Alojado en la página web del IFEA http://www.ifeanet.org/piruru/piruru.htm 


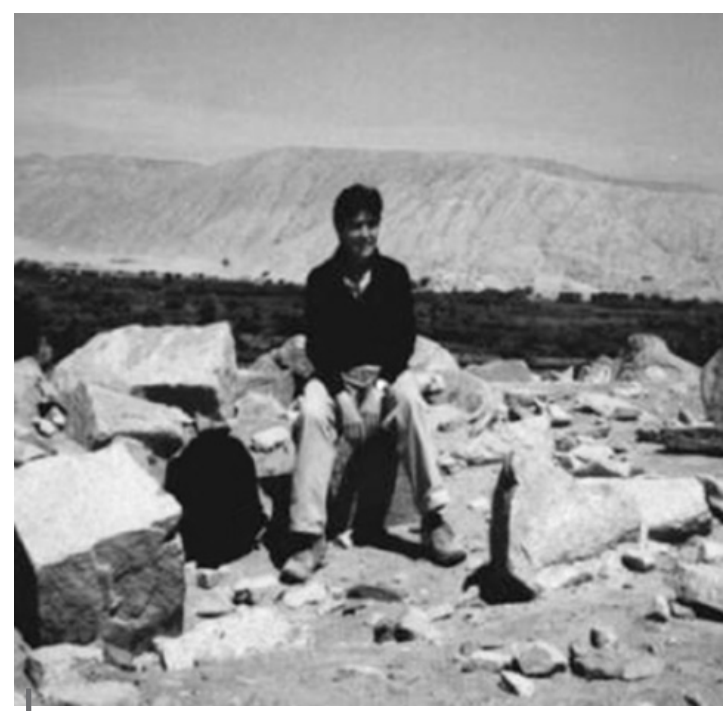

Elisabeth Bonnier Foto Alina Wong

Era 2004, viajamos nuevamente a San de Pedro de Cajas (Junín), un nuevo tema de investigación se perfilaba y estaba relacionado con uno de los sitios tardíos que ya había trabajado para su tesis de doctorado. Estaba interesada en el proceso y en la distribución de la sal. A la luz de los últimos descubrimientos hechos en el valle de Supe, era obligatorio nuestro paso por Caral. En 2005 regresó una vez más al Perú con sus hijos Philippe y Paul para mostrarles el país donde había trabajado y vivido por muchos años. Después de visitar los tradicionales Cuzco y Nazca, regresamos a los orígenes... Tantamayo. Fuimos más allá, donde se estrecha el río Marañón, y llegamos a Urpish, un centro amurallado con edificios de varios pisos en el límite norte.

Participó en el $« 53^{\circ}$ Congreso Internacional de Americanistas» realizado en Sevilla en la Mesa «Explicando los orígenes de la civilización en los Andes centrales: una perspectiva regional y de conjunto», que tuvo lugar el 19 de julio de 2006 con la ponencia «De la arquitectura como testigo de desarrollo cultural y social. El caso Mito».

Nuevamente volvió al Perú en agosto de 2007 y trabajó exclusivamente en el IFEA, para afinar los últimos detalles de la preparación de su ensayo Arquitectura precerámica en los Andes. La tradición Mito; una versión en español de su artículo «Preceramic architecture in the Andes: the Mito tradition», que contenía una nueva revisión e introducción a la luz de otros ejemplos de arquitectura ceremonial temprana, recién aparecidos en la literatura arqueológica. Dejó, aún en prensa, su último artículo «Imágenes de la arquitectura Mito» (2008).

Elisabeth era una investigadora a carta cabal, dotada de una inusitada fuerza, una apasionada de la arqueología y, ciertamente, una enamorada del Perú que tenía aún muchos planes. A pesar de su enfermedad siguió viviendo al máximo cada momento, consciente o inconscientemente de que sería su última vez; era su manera de sacarle la vuelta al cáncer y al tiempo. Trabajar con ella durante varias temporadas, tanto en el campo como en el laboratorio, fue una experiencia enriquecedora de aprendizaje en lo profesional y en lo personal. Aprendimos de ella la rigurosidad metodológica de la escuela francesa, la importancia del registro del dato arqueológico dentro de su contexto cronoestratigráfico que, evidentemente, son la base de toda investigación seria.

En los últimos años se propuso regresar al Perú (me atrevería a decir, uno de los lugares donde fue feliz) y lo hizo. La recordaremos cabalgando a lomo de acémila o caminando en las alturas de los Andes, así como lo hizo muchas veces Bertrand Flornoy. También tendremos la imagen grabada en la retina de los momentos de trabajo duro y tensión vividos en Piruru, de los instantes de intercambio intelectual, de las animadas charlas sobre la problemática de la arquitectura y de la arqueología peruana o simplemente de las noticias de nuevas investigaciones. Verla disfrutando de un café humeante, de un buen pisco, de un juego de cartas al final de una agotadora jornada. Sí, la vamos a extrañar. 


\section{Bibliografía}

BONNIER, E., 1980 - Projet Tantamayo Piruru. Première partie: Les sites archéologiques, 25 pp.; París: Centre national de recherche scientifique. CNRS.

BONNIER, E., 1981 - Las ruinas de Tantamayo: vestigios de una ocupación tardía, provincia de Huamalíes, departamento de Huánuco. Boletín de Lima, 14: 38-53; Lima.

BONNIER, E., 1983 - Piruru: nuevas evidencias de ocupación temprana en Tantamayo, Perú. Gaceta arqueológica andina, 2 (8): 8-10; Lima.

BONNIER, E., 1986 - Utilisation du sol à l'époque préhispanique : le cas archéologique du Shaka-Palcamayo (Andes Centrales). Cahiers des Sciences Humaines, 22 (1): 97-113; París.

BONNIER, E., 1987 - Les architectures précéramiques dans la Cordillère des Andes : Piruru face à la diversité des données. L'Anthropologie, 91 (4): 889-904; París.

BONNIER, E., 1987-1988 - The earliest architecture and the beginning of sedentarism in the peruvian highlands: Tantamayo Piruru project. Willay: Newsletter of the andean anthropological research group, 26-27: 6-8; Cambridge.

BONNIER, E., 1988a - Acerca del surgimiento de la arquitectura en la sierra andina. In: I Simposium: Arquitectura y arqueología: Pasado y futuro de la construcción en el Perú (V. Rangel Flores, ed.); Chiclayo: Universidad de Chiclayo-Museo Bruning. 13-16 agosto 1988.

BONNIER, E., 1988b - Arquitectura precerámica en la cordillera de los Andes, Piruru frente a la diversidad de los datos. Anthropologica, 6: 335-361; Lima.

BONNIER, E., 1997a - Morfología del espacio aldeano y su expresión cultural en los Andes centrales. In: Arquitectura y civilización en los Andes prehispánicos = Prehispanic architecture and civilization in the Andes (E. Bonnier \& H. Bischof, eds.): 29-41; Mannheim: Sociedad arqueológica peruano-alemana, Reiss-Museum. Archaeologica peruana, 2.

BONNIER, E., 1997b - Preceramic architecture in the Andes: the mito tradition. In: Arquitectura y civilización en los Andes prehispánicos = Prehispanic architecture and civilization in the Andes (E. Bonnier \& H. Bischof, eds.): 121-144; Mannheim: Sociedad arqueológica peruano-alemana, Reiss-Museum. Archaeologica peruana, 2.

BONNIER, E., 2007 - Arquitectura precerámica en los Andes: la tradición Mito, 97 pp.; Lima: Institut français d'Études andines-IFEA, Lluvia Editores. Colección Biblioteca andina de bolsillo, 27.

BONNIER, E. \& BISCHOF, H. (eds.), 1997 - Arquitectura y civilización en los Andes prehispánicos = Prehispanic architecture and civilization in the Andes, 236 pp.; Mannheim: Sociedad arqueológica peruano-alemana, Reiss-Museum. Archaeologica peruana, 2.

BONNIER, E., HOWARD, R., KAPLAN, L. \& ROZENBERG, C., 1983 - Recherches archéologiques, paléobotaniques et ethnolinguistiques dans une vallée du Haut Marañón (Pérou) : le projet Tantamayo-Piruru. Bulletin de l'Institut français d'Études andines, 12 (1-2): 103-133; Lima.

BONNIER, E. \& ROZENBERG, C., 1977 - Eléments pour une analyse morphologique de la céramique. Bulletin de l'Institut français d'Études andines, 6 (3-4): 3-24; Lima.

BONNIER, E. \& ROZENBERG, C., 1978a - L'habitat en village à l'époque préhispanique dans le bassin Shaka-Palcamayo, département de Junín-Pérou. Bulletin de I'Institut français d'Études andines, 7 (1-2): 49-71; Lima. 
BONNIER, E. \& ROZENBERG, C., 1978b - Note complémentaire sur l'habitat en village, à l'époque préhispanique, dans le bassin Shaka-Palcamayo (dpt. de Junín, Pérou). Bulletin de l'Institut français d'Études andines, 7 (3-4): 59-60; Lima.

BONNIER, E. \& ROZENBERG, C., 1979 - Les sites tardifs : I'habitat en village. In: Mission archéologique française à Junín : Recherches sur l'habitat préhistorique dans les Andes centrales du Pérou: 5-23; París: Unité de recherche archéologiques. URA 25, Institut français d'Études andines-IFEA.

BONNIER, E. \& ROZENBERG, C., 1981 - Proyecto Tantamayo-Piruru. Kotosh: revista de cultura, 6: 19-23; Huánuco.

BONNIER, E. \& ROZENBERG, C., 1982 - L'Occupation humaine dans le bassin du Shaka-Palcamayo à I'Intermédiaire Récent, Andes Centrales du Pérou, 3 t.; París: Université de Paris X-École des hautes études en sciences sociales. EHESS. Tesis de tercer ciclo.

BONNIER, E. \& ROZENBERG, C., 1987 - El proyecto Tantamayo Piruru. Arqueología en un valle del Alto Marañón. Kuntur, Perú en la Cultura, n. ${ }^{\circ}$ 3: 3-9.

BONNIER, E. \& ROZENBERG, C., 1988a - Du sanctuaire au hameau. À propos de la néolithisation dans la cordillère des Andes centrales. L'Anthropologie, 92 (3): 983996; París.

BONNIER, E. \& ROZENBERG, C., 1988b - Del santuario al caserío: acerca de la neolitización en la Cordillera de los Andes Centrales. Bulletin de I'Institut français d'Études andines, 17 (2): 23-40; Lima.

BONNIER, E. \& SUNDSTROM, M., 2007 - Piruru interactivo. http://www.ifeanet.org/ piruru/piruru.htm

BONNIER, E., ZEGARRA, J. \& TELLO, J. C., 1985 - Un ejemplo de crono-estratigrafía en un sitio con superposición arquitectónica: Piruru-Unidad I/II. Bulletin de I'Institut français d'Études andines, 14 (3-4): 80-101; Lima.

FLORNOY, B., 1957 - Monuments de la région de Tantamayo (Pérou). Journal de la Société des Américanistes, T. XLV: 207-225; París.

KAPLAN, L. \& BONNIER, E., 1986 - Piruru: a preliminary report on the archaeological botany of a highland andean site. In: Perspectives on Andean Prehistory and Protohistory (D. Sandweiss \& P. Kvietok, eds.): 115-121; New York: Cornell University.

LACLAVÈRE, G., 1981 - Bertrand Flornoy. Bulletin d'Information et de Liaison, n. ${ }^{\circ}$ 3; París.

LAVALLÉE, D., JULIEN, M., WHEELER, J. \& KARLIN, C., 1995 - Telarmachay. Cazadores y pastores prehistóricos de los Andes, 2 tomos, 445 pp.; Lima: Institut français d'Études andines.

OCAÑA LAGO, C., 2007 - Tantamayo bajo la sombra de Sendero: Testimonio de una época cruenta; Huánuco: Ed. Rascacielos.

SAIGNES, T., 1979 - Louis Girault (1919-1975). Journal de la Société des Anéricanistes, T. 66: 287; París.

GIRAULT, L., 1981 - Fouilles sur le site de Piruru en 1968 et 1970. Bulletin de I'Institut français d'Études andines, T. X (1-2): 101-102. Publicado por E. Bonnier. E. \& C. Rozenberg. 